\title{
Assessment of the wave energy resource in the South China Sea
}

\section{Bo Jiang MSC}

Associate Research Fellow, National Ocean Technology Center, Tianjin, China (corresponding author: qdjiangbo@163.com) (Orcid:0000-0003-3571-1198)

\section{Guowei Wu MSc}

Assistant Engineer, National Ocean Technology Center, Tianjin, China Jie Ding MSC

Engineer, National Ocean Technology Center, Tianjin, China

\author{
Changlei Ma MSC \\ Senior Engineer, National Ocean Technology Center, Tianjin, China \\ Yizhou Fang MSC \\ Assistant Engineer, National Ocean Technology Center, Tianjin, China \\ Xiaoyng Wang MSC \\ Professor, National Ocean Technology Center, Tianjin, China
}

Assessments of wave energy resources form the basis of plans for developing and using wave energy, and provide guidance about where to site wave power stations and how to design wave energy convertors. Various indexes, including the spatial and temporal distributions of wave energy fluxes, the occurrence of the effective significant wave height, monthly and seasonal variability and the frequency of high sea states, were calculated from the recent 37-year European Centre for Medium-Range Weather Forecasts ERA-Interim reanalysis of wave field data. The results showed that areas with abundant and stable exploitable wave energy in the South China Sea were mainly between the Luzon Strait and the southeast of the Indo-China Peninsula, where the annual average wave energy fluxes ranged from 10 to $18 \mathrm{~kW} / \mathrm{m}$ and the monthly and seasonal variability indexes were less than 2.2 and 1.6 , respectively. The wave energy was found to be poor in some coastal areas of the Beibu Gulf, the Gulf of Thailand and the Sulu Sea. In the areas where wave energy was abundant, high sea states occurred frequently, meaning that it was relatively difficult to use the energy. Therefore, the wave energy resources and the frequency of high sea states need to be considered when choosing sites for wave energy farms.

\section{Notation}

g gravitational acceleration $(\mathrm{N} / \mathrm{kg})$

$H_{1 / 3} \quad$ significant wave height (m)

$N \quad$ total number of data points

$P_{\mathrm{w}} \quad$ wave energy flux $(\mathrm{W} / \mathrm{m})$

$T_{\mathrm{e}} \quad$ energy period (s)

$x_{i} \quad$ measured data

$\bar{x}, \bar{y} \quad$ mean value of the measured and the European Centre for Medium-Range Weather Forecasts ERA-Interim reanalysis data, respectively

$y_{i} \quad$ ERA-Interim reanalysis data

$\rho \quad$ density of the sea water $\left(\mathrm{kg} / \mathrm{m}^{3}\right)$

\section{Introduction}

Against the backdrop of the crisis in natural resources, the ongoing development of renewable energy resources is needed to deal with the energy crisis (Wan et al., 2015a; Zheng and Pan, 2014).

The first general investigation and assessment of wave energy resources in China (organised by the Chinese Ministry of Water and Electricity and the Chinese State Oceanic Administration) was based on observed data collected from numerous ocean observation stations during the 1980s and represented the first estimate of the Chinese wave energy resource (Wang, 1984a, 1984b). The total wave energy power calculated at that time was approximately $70 \mathrm{GW}$ and the results showed that the wave energy resource varied significantly, both regionally and seasonally, and that it gradually decreased from south to north, and was large in autumn and winter and small in spring and summer. However, while this first investigation was useful, experience in recent years has shown that the estimates of the wave energy resource were too simple and crude. In principle, the wave energy climate can be assessed from measurements; however, because it is difficult to maintain wave measuring instruments over a long period of time, other data collection methods such as wave models, X-band radar and satellite remote sensing have been considered.

Over recent years, the Chinese coastline has been transformed due to rapid development in coastal areas and the construction of marine engineering facilities, such that the results from the first investigation are no longer representative of the distribution of wave energy resources in China. A second general investigation and assessment was therefore initiated by the State Council of China in 2003, in which the wave energy resources were calculated and analysed using the third-generation spectral wave model (Swan) (Zhang et al., 2012). The numerical wave model was validated with measurements from 27 wave measuring instruments collected by 
acoustic Doppler current profilers (ADCPs) and pressure sensors over a period of 1 year. Based on the assumption that wave energy is available in areas where the annual mean wave energy flux is greater than $1 \mathrm{~kW} / \mathrm{m}$, the available wave energy in China was estimated to be $14.7 \mathrm{GW}$. The second general investigation and assessment of wave energy resource included a macro-level presentation of the distribution of China's wave energy resources, derived from the statistics of the quantity of the wave resource. However, this investigation only evaluated natural resources and included data for only a few criteria from a limited number of survey stations, and so did not provide comprehensive scientific information that can be used to guide the design and operation of wave energy farms and wave energy converters (WECs).

The Ministry of Finance and the State Oceanic Administration of China established a special fund for ocean Renewable energy in 2010. The third general investigation and assessment for wave energy resources, initiated in 2011, used data from more than 1 month in each season collected by buoys, ADCPs, X-band radar and synthetic aperture radar at more than 40 stations, 10-year numerical simulations from 2003 to 2012 and the 37-year European Centre for Medium-Range Weather Forecasts (ECMWF) ERA-Interim reanalysis data for the period from 1979 to 2015 (Jiang et al., 2017; Wan et al., 2014, 2015a, 2015b). In this third general investigation and assessment, the State Oceanic Administration of China developed detailed high-resolution maps of the wave energy resource in specific regions of the Bohai Sea, Yellow Sea $\left(1^{\prime} \times 1^{\prime}\right)$ and the East China Sea $\left(2^{\prime} \times 2^{\prime}\right)$ (Jiang et al., 2017). The simulated results were validated and adjusted by wave measurements from 40 stations. The wave energy resource in the areas of the South China Sea that were not covered by the model system was assessed with the ERA-Interim reanalysis data. The wave energy map of the South China Sea was developed with geographic information systems and the wave energy availability off an off shore $20 \mathrm{~km}$ continuous line along the Bohai Sea, Yellow Sea and the East China Sea was estimated at 642, 2117 and 7709 MW, respectively.

This study is part of the third general investigation and assessment of wave energy resources. Various indexes, including the spatial and temporal distribution of the wave energy flux, the occurrence of the effective significant wave height, monthly and seasonal variability and the high sea state frequency (HSSF) were calculated from the recent 37-year ERA-Interim reanalysis of wave field data. This research study will provide the basis for future wave energy assessments and will be valuable for guiding the choice of sites for wave energy farms.

This paper includes $(a)$ a description of the wave field data that were used to estimate the wave energy, $(b)$ details about the wave energy resources in the South China Sea and (c) detailed information about various indexes that were used to describe the theoretical wave energy and the exploitable wave energy. The results are followed by a summary and conclusions.

\section{Wave field data}

\subsection{ECMWF ERA-Interim reanalysis datasets}

The ERA-Interim reanalysis data are hosted by the ECMWF and have been evaluated and used extensively (Wan et al., 2015a; Zheng et al., 2013a, 2014; Zhou et al., 2011). The wave model of the ECMWF, known as WAM (Andersson, 2013), describes the rate of change of the two-dimensional wave spectrum in any water depth caused by advection, wind input, dissipation due to white capping, and bottom friction and nonlinear wave interactions (Andersson, 2013). Radar altimeter wave-height data are assimilated from satellites. Buoy wave data are not assimilated, but instead are used to independently check the quality of modelled wave parameters (Andersson, 2013).

In this paper, the high-resolution wave field data $\left(0.125^{\circ} \times 0.125^{\circ}\right)$ from ECMWF ERA-Interim that included the significant height of the combined wind-wave, swell $\left(H_{1 / 3}\right.$ (in $\mathrm{m}$ )) and the energy period $\left(T_{\mathrm{e}}\right.$ (in s)) were used. Wave field data from 1 January 1979 to 31 December 2015, that covered the area from $0^{\circ} \mathrm{N}$ to $23 \cdot 5^{\circ} \mathrm{N}$ and from $100^{\circ} \mathrm{E}$ to $122^{\circ} \mathrm{E}$, at spatial and temporal resolutions of $0.125^{\circ} \times 0.125^{\circ}$ and $6 \mathrm{~h}$, respectively, were used in this study.

\subsection{Data verification}

In this study, wave data from a buoy and two ADCP moorings in the South China Sea (Table 1) were used to verify the

Table 1. Description of the buoy stations

\begin{tabular}{|c|c|c|c|c|c|}
\hline ID & Longitude & Latitude & Data period: $\mathrm{mm} / \mathrm{dd} / \mathrm{yyyy}$ & Instrument & Time interval: $\mathbf{h}$ \\
\hline 1 & $116^{\circ} 26^{\prime} 24^{\prime \prime}$ & $22^{\circ} 52^{\prime} 06^{\prime \prime}$ & $\begin{array}{l}11 / 04 / 2011 \text { to } 12 / 31 / 2011 ; \\
05 / 01 / 2012 \text { to } 06 / 30 / 2012\end{array}$ & $A D C P$ & 0.5 \\
\hline 2 & $116^{\circ} 18^{\prime} 12^{\prime \prime}$ & $22^{\circ} 51^{\prime} 48^{\prime \prime}$ & $\begin{array}{l}11 / 04 / 2011 \text { to } 12 / 31 / 2011 \\
05 / 01 / 2012 \text { to } 06 / 30 / 2012\end{array}$ & $A D C P$ & 0.5 \\
\hline 3 & $115^{\circ} 35^{\prime} 24^{\prime \prime}$ & $22^{\circ} 16^{\prime} 48^{\prime \prime}$ & $\begin{array}{l}11 / 01 / 2011 \text { to } 12 / 31 / 2011 \\
05 / 01 / 2012 \text { to } 06 / 30 / 2012\end{array}$ & Buoy & 0.5 \\
\hline
\end{tabular}


accuracy of the ERA-Interim reanalysis data. The significant wave height and the energy period are two basic parameters for calculating the wave energy flux. Comparisons of the time series of the measurement-derived and ECMWF ERA-Interim significant wave height and energy period at a temporal resolution of $6 \mathrm{~h}$ (Figures 1 and 2) showed that there was reasonable agreement between the measured and ERA-Interim data over the selected time period and so the ERA-Interim wave field data were considered reliable for assessing the wave energy resource.
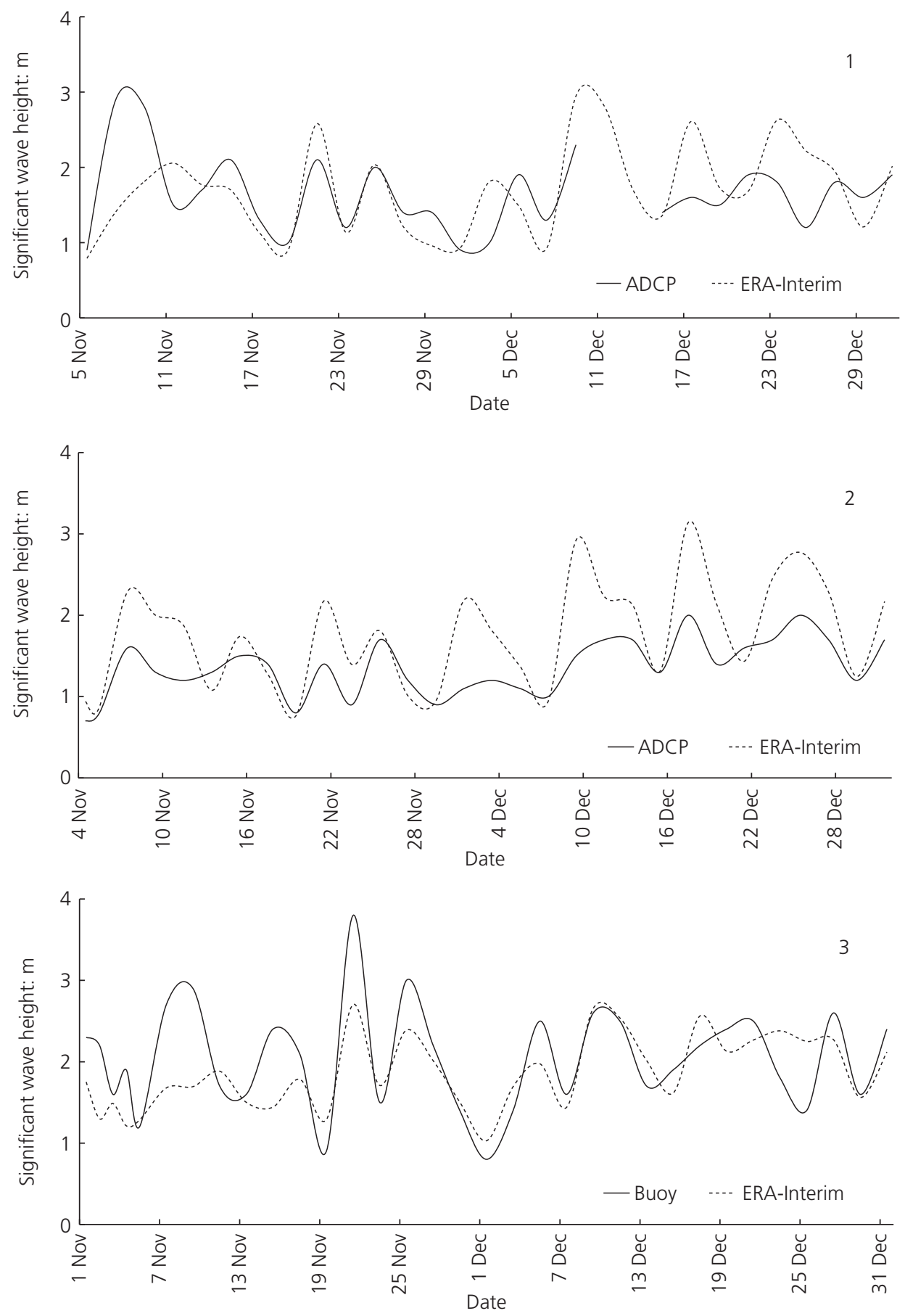

Figure 1. Comparison of the ERA-Interim and measurement-derived significant wave heights 

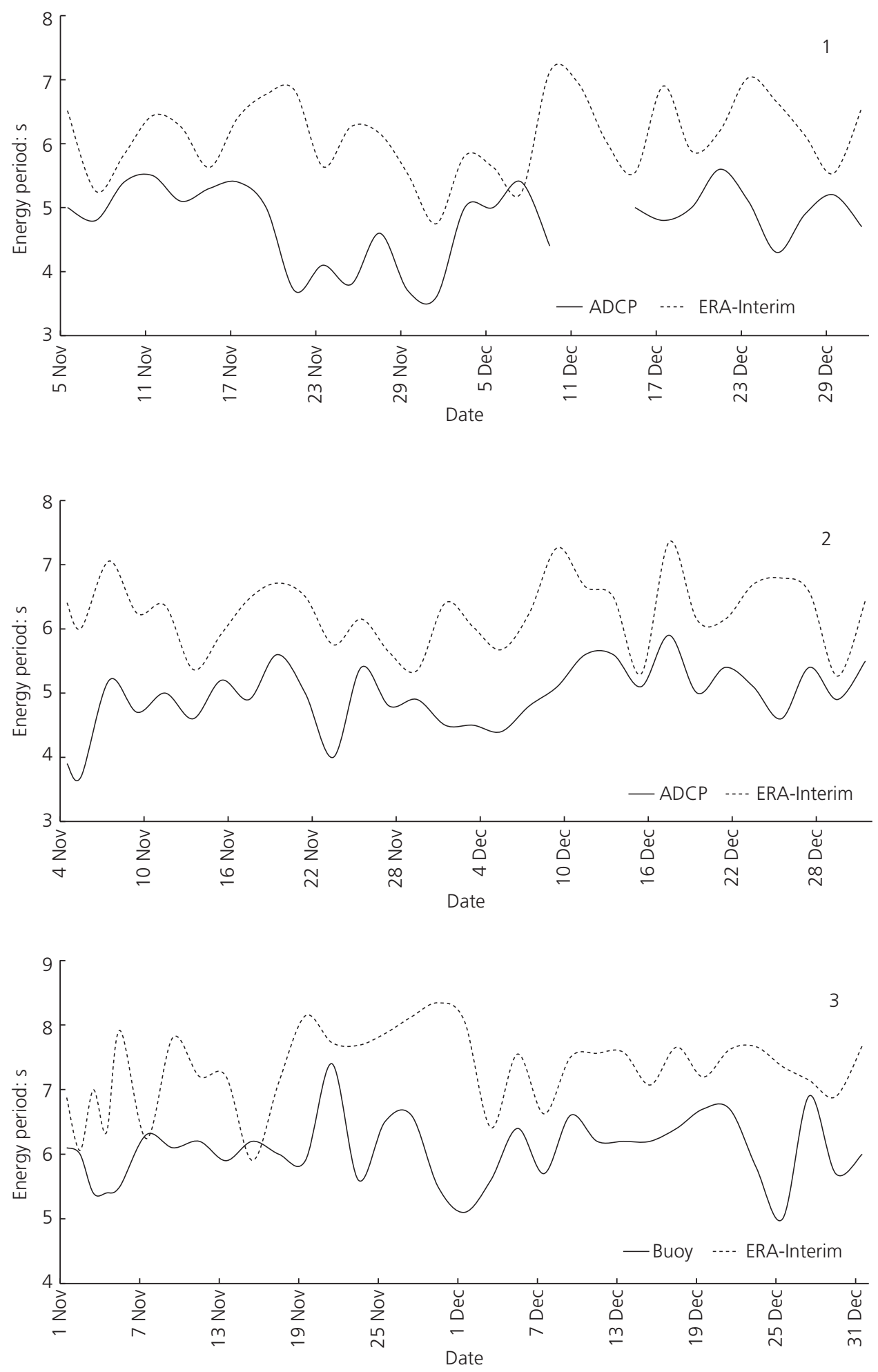

Figure 2. Comparison of the ERA-Interim and measurement-derived energy periods 
The indexes used to evaluate the accuracy included the correlation coefficient $(R)$, bias and the root mean square error (RMSE), calculated as

1. $R=\frac{\sum_{i=1}^{N}\left(\left(x_{i}-\bar{x}\right) \times\left(y_{i}-\bar{y}\right)\right)}{\sqrt{\sum_{i=1}^{N}\left(x_{i}-\bar{x}\right) \sum_{i}^{N}\left(y_{i}-\bar{y}\right)^{2}}}$

2. $\quad \operatorname{Bias}=\bar{y}-\bar{x}$

3. $\quad \mathrm{RMSE}=\sqrt{\frac{1}{N} \sum_{i=1}^{N}\left(x_{i}-y_{i}\right)^{2}}$

where $x_{i}$ is the measured data, $y_{i}$ represents the ERA-Interim reanalysis data, $\bar{x}$ and $\bar{y}$ are the mean values of the measured and the ERA-Interim reanalysis data, respectively, and $N$ is the total number of data points. The error indexes of wind speed are listed in Table 2.

As shown in Table 2, the ERA-Interim reanalysis data generally agreed well with the measurements of sites 1,2 and 3. For the significant wave height, the values of $R$ for the three sites were higher than $0 \cdot 74$, the bias values were below $0.19 \mathrm{~m}$ and the RMSE values were less than $0.48 \mathrm{~m}$; for the mean period, the values of $R$ for all three sites were greater than 0.52 , the bias values were less than $1.47 \mathrm{~s}$ and the RMSE values were less than $1.68 \mathrm{~s}$

These results show that the wave field data for the South China Sea from the ERA-Interim reanalysis data were accurate enough for the purposes of this study.

\section{Assessment of the wave energy resource in the South China Sea}

The wave energy flux was calculated as (Goncalves et al., 2014; Liang et al., 2014)

4. $\quad P_{\mathrm{w}}=\frac{\rho \boldsymbol{g}^{2}}{64 \pi} \times H_{1 / 3}^{2} \times T_{\mathrm{e}}$

where $P_{\mathrm{w}}$ is the wave energy flux $(\mathrm{W} / \mathrm{m}), \rho$ is the density of the sea water $\left(\mathrm{kg} / \mathrm{m}^{3}\right), \boldsymbol{g}$ is the gravitational acceleration $(\mathrm{N} / \mathrm{kg})$,

Table 2. Indicators of the error between the ERA-Interim reanalysis data and the observed data

\begin{tabular}{|c|c|c|c|c|c|c|}
\hline \multirow[b]{2}{*}{ Site } & \multicolumn{3}{|c|}{ Significant wave height } & \multicolumn{3}{|c|}{ Energy period } \\
\hline & $R$ & Bias: $m$ & RMSE: $m$ & $R$ & Bias: $s$ & RMSE: $s$ \\
\hline 1 & 0.80 & 0.02 & 0.17 & 0.52 & $-1 \cdot 47$ & 1.68 \\
\hline 2 & 0.74 & -0.19 & 0.48 & 0.58 & $-1 \cdot 31$ & 1.50 \\
\hline 3 & 0.86 & 0.16 & 0.42 & 0.67 & -0.97 & $1 \cdot 20$ \\
\hline
\end{tabular}

$H_{1 / 3}$ is the significant wave height $(\mathrm{m})$ and $T_{\mathrm{e}}$ is the energy period (s). The wave energy flux in the South China Sea for the period from 1 January 1979 until 31 December 2015 at a temporal resolution of $6 \mathrm{~h}$ and a spatial resolution of $0 \cdot 125^{\circ} \times 0 \cdot 125^{\circ}$ was obtained by applying Equation 4 to the ERA-Interim reanalysis data.

\subsection{Temporal and spatial distributions of the wave energy flux}

There were obvious seasonal and regional variations in the wave energy flux in the South China Sea. The annual and seasonal average wave energy flux distributions in the South China Sea calculated from the recent 37-year ERA-Interim data are shown in Figure 3.

The wave energy flux is a key parameter in calculations of the wave energy resource. Zheng et al. (2013b) indicated that waves with an annual average energy flux exceeding $2 \mathrm{~kW} / \mathrm{m}$ could be used. As presented in Figure 3(a), with the exception of the coastal waters, the annual average wave energy flux of the majority of the South China Sea was greater than $2 \mathrm{~kW} / \mathrm{m}$, which shows that wave energy can be exploited across most of the South China Sea. The annual average wave energy flux was highest $(10-18 \mathrm{~kW} / \mathrm{m})$ between the Luzon Strait and the southeast of Indo-China Peninsula and reached a maximum of $18 \mathrm{~kW} / \mathrm{m}$ in the Luzon Strait.

The wave energy fluxes in winter (December, January and February (DJF)) and autumn (September, October and November (SON)) were considerably larger than those in spring (March, April and May (MAM)) and summer (June, July and August (JJA)). There were also considerable regional differences. Under the influence of the northeast monsoon in winter, the wave energy flux was high $(10-28 \mathrm{~kW} / \mathrm{m})$ across a large area distributed roughly from the northeast to the southwest, and reached a maximum in the seas adjacent to the Dongsha Islands and to Pingshun Island in the southeast of the Indo-China Peninsula, where they were above 28 and $22 \mathrm{~kW} / \mathrm{m}$, respectively. The areas with high wave energy flux values in autumn and winter were similar $(10-20 \mathrm{~kW} / \mathrm{m})$, and reached a maximum in the seas adjacent to the Dongsha Islands $(>20 \mathrm{~kW} / \mathrm{m})$. In spring and summer, the wave energy flux values were highest $(10-12 \mathrm{~kW} / \mathrm{m})$ in the Luzon Strait. In each season, the wave energy flux was less than $4 \mathrm{~kW} / \mathrm{m}$ in the Beibu Gulf, the Gulf of Thailand, Sulu Sea and the seas adjacent to the equator. The winter and autumn seasons are thus the most important periods for exploiting the wave energy resources in the South China Sea.

\subsection{Occurrence of the effective significant wave height}

The effective significant wave height is defined as the value of the significant wave height that is large enough to meet the 


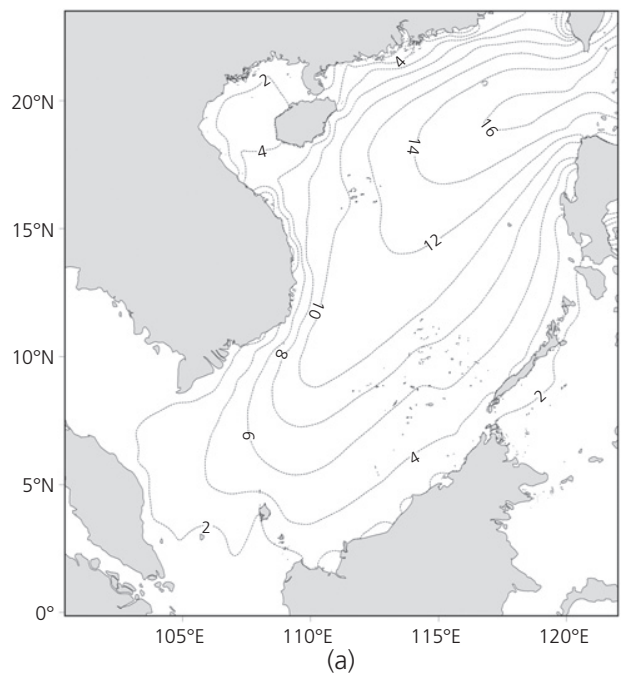

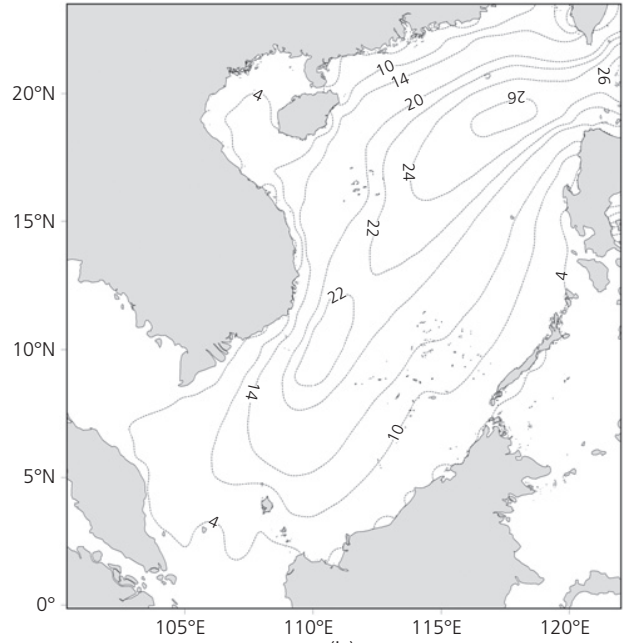

(b)

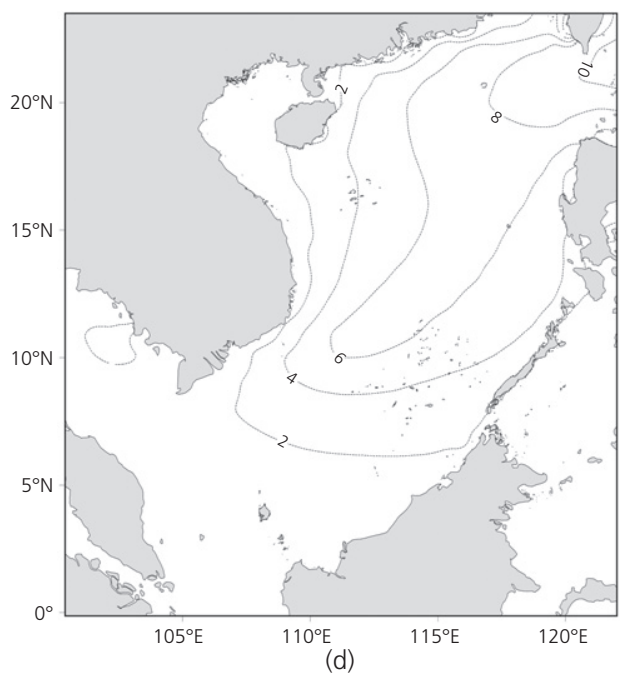

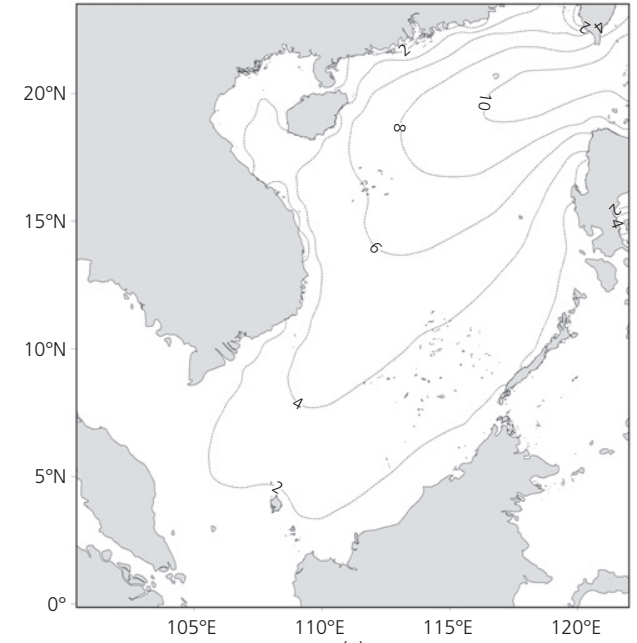

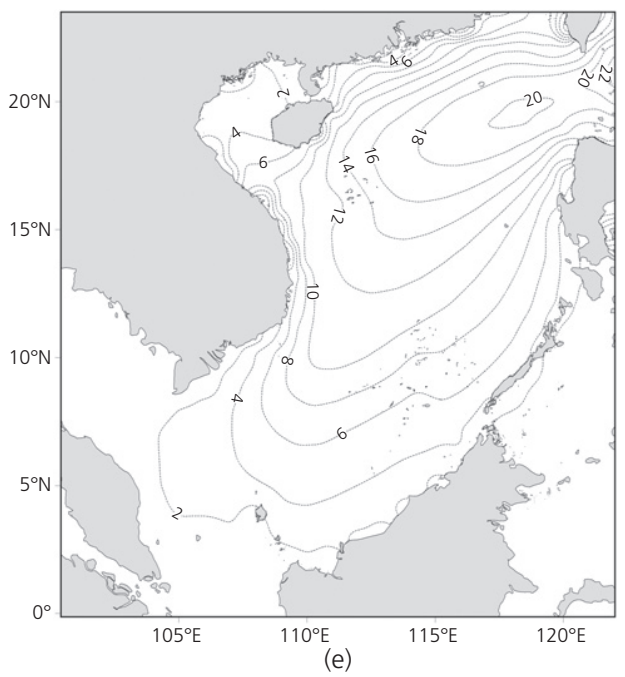

Figure 3. Annual and seasonal average wave energy flux over the past 37 years (unit: kW/m): (a) annual; (b) winter (DJF); (c) spring (MAM); (d) summer (JJA); (e) autumn (SON) 
practical application needs of WECs, including their operational safety and running requirements (Wan et al., 2015a). Rough and disruptive waves during high seas, such as during typhoons and storm surges, pose serious threats to the safety of WECs. Zheng et al. (2013b) indicated that some welldesigned WECs could absorb wave energy when the significant wave height is greater than $0.5 \mathrm{~m}$ but would be seriously damaged when the significant wave height is greater than $4 \mathrm{~m}$. Sheng et al. (2017) suggest that the Sharp Eagle Wanshan WEC can generate electricity intermittently with mild waves that are only $0.5 \mathrm{~m}$ high and could survive wave heights of up to $4 \mathrm{~m}$. In this paper, the effective significant wave height for WECs ranged from 0.5 to $4 \mathrm{~m}$.

The occurrence of the effective significant wave height on annual and seasonal timescales was calculated from the $6 \mathrm{~h}$ significant wave height data for the period from 1979 to 2015 (Figure 4).

Regardless of the season, the wave height in the South China Sea was between 0.5 and $4 \mathrm{~m}$ for $60 \%$ of the year, except in some small areas close to the equator and some coastal waters such as the Beibu Gulf, the Gulf of Thailand and Sulu Sea, which means one can be optimistic about the development of wave energy resources. Examination of the annual pattern over the past 37 years (Figure 3(a)) showed that the effective significant wave height was consistently high over large areas of the north-central part of the South China Sea $(>90 \%)$, with the maximum between the east of Hainan Island to the south of Taiwan Island $(>99 \%)$ and the minimum in the areas mainly near the shore. During winter, the effective significant wave height was high in the southern and northern parts of the South China Sea $(>99 \%)$. In spring, summer and autumn, the effective significant wave height was high in the northern part of the South China Sea $(>99 \%$ in spring and summer, $>98 \%$ in autumn). The most important areas for the development of wave energy resources are thus the northern part of the South China Sea all year round and the southern part of the South China Sea in winter.

\subsection{Monthly and seasonal variability indexes}

Several studies have shown that, as well as the wave energy flux, the stability also needs to be considered when assessing wave energy resources (Wan et al., 2015a; Zheng et al., 2013b), as it is easier to exploit and use a stable energy supply. An unstable energy supply may damage or even destroy WECs and the energy conversion efficiency will be lower than for a stable supply. The stability over a period of a month was quantified using the monthly variation (MV) in the wave energy. The MV is given by

5. $\mathrm{MV}=\left(P_{\max }-P_{\min }\right) / P_{\text {year }}$ where $P_{\max }$ is the month with the highest wave energy flux, $P_{\min }$ is the month with the lowest wave energy flux and $P_{\text {year }}$ is the annual average wave energy flux. The greater the MV, the more unstable the energy supply through the month.

As shown in Figure 5, the MV of the wave energy flux was below 2.0 across most of the South China Sea, which means that the wave energy flux in most areas does not vary strongly on a monthly basis (the distribution of the MV index is presented in Table 3). However, there were obvious spatial variations in the MV index, and it was generally lower in the northeast of the South China Sea than in the southwest, which indicates that the wave energy flux is more stable in the northeast of the South China Sea than in the southwestern part when assessed on a monthly basis. The monthly stability was lowest from the south of the Indo-China Peninsula to the northwest of Kalimantan Island, and the MV exceeded 2.8 to the north of Kuchin, Malaysia.

Another index was calculated to show the seasonal variation in the wave energy flux (SV). As the values of the SV increase, the seasonal stability decreases. The SV was calculated using

$$
\text { 6. } \mathrm{SV}=\left(P_{S_{\max }}-P_{S_{\min }}\right) / P_{\text {year }}
$$

where $P_{S_{\max }}$ is the season with the highest wave energy flux, $P_{S_{\min }}$ is the season with the lowest wave energy flux and $P_{\text {year }}$ is the annual average wave energy flux.

Overall, the distribution of the SV of the wave energy flux was similar to that of the MV. Numerically, the values of the SV were lower than those of the MV, with values lower than 1.6 across most of the South China Sea, altough the overall distributions of the two indexes were similar, as shown in Figures 5 and 6, respectively.

\subsection{HSSF}

Wang et al. (2017) indicated that the self-protection mechanism of the Sharp Eagle Wanshan WEC engages when the wave height exceeds $4 \mathrm{~m}$. However, Zheng et al. (2013b) indicated that WECs would be damaged when the significant wave height is higher than $4 \mathrm{~m}$. A new parameter, the HSSF, was introduced to examine how a high sea state might influence WECs in the South China Sea. The HSSF was defined as the frequency of waves with a significant wave height higher than $4 \mathrm{~m}$ in the last 37 years. The distribution of the HSSF in the South China Sea is shown in Figure 7.

As shown in Figure 7, the HSSF annual values $(>2.5 \%)$ were high in the northern part of the South China Sea $\left(15^{\circ} \mathrm{N}-20^{\circ} \mathrm{N}\right.$, $115^{\circ} \mathrm{E}-120^{\circ} \mathrm{E}$ ). The HSSF was lower in coastal waters (usually $<0.5 \%$ ) than in the centre of the South China Sea. The northeast monsoon, active in winter and autumn, means that 


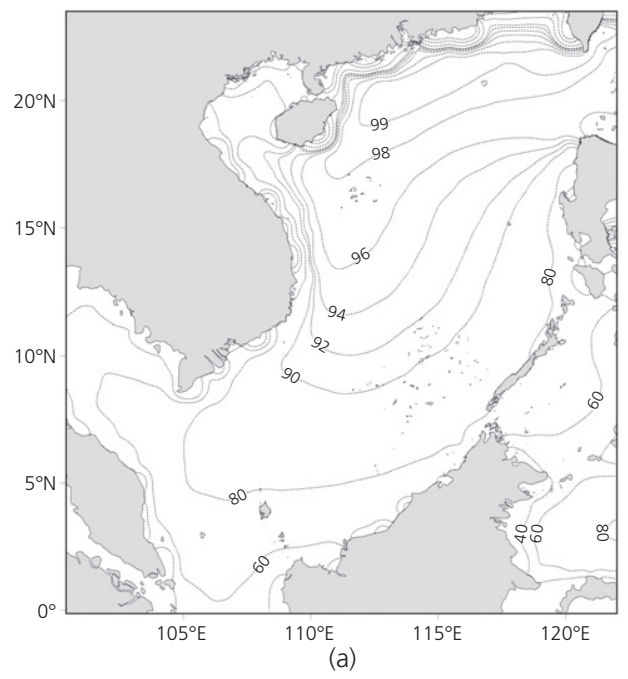

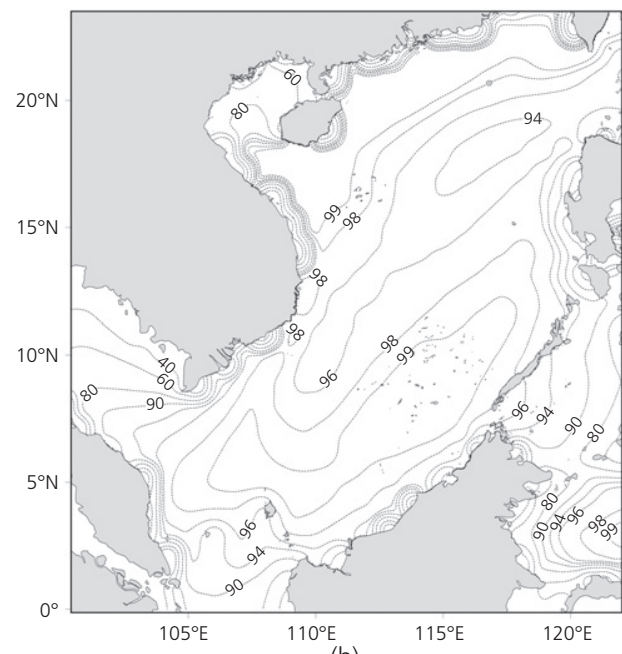

(b)

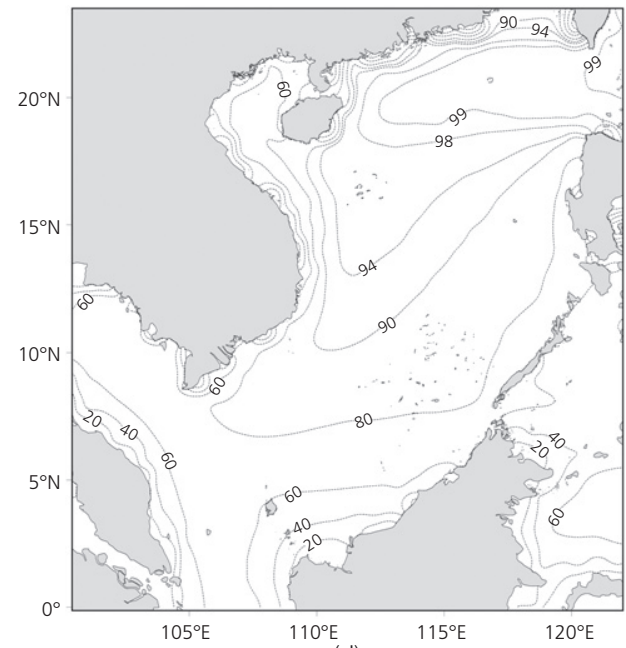

(d)

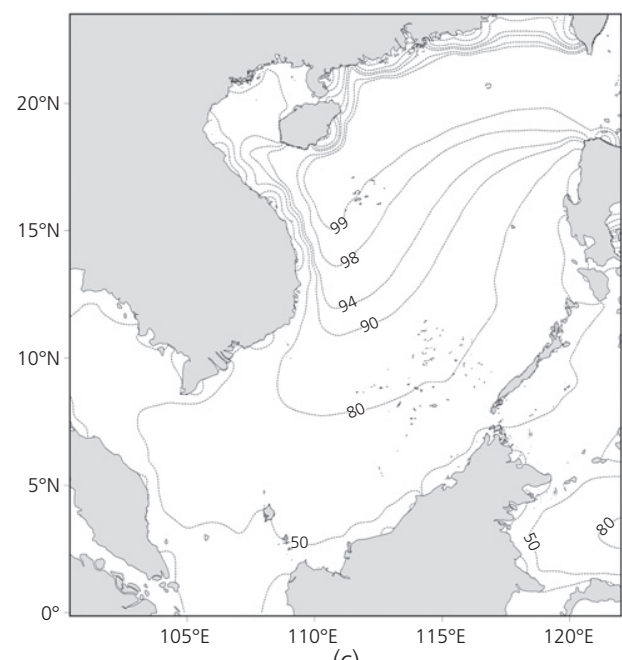

(c)

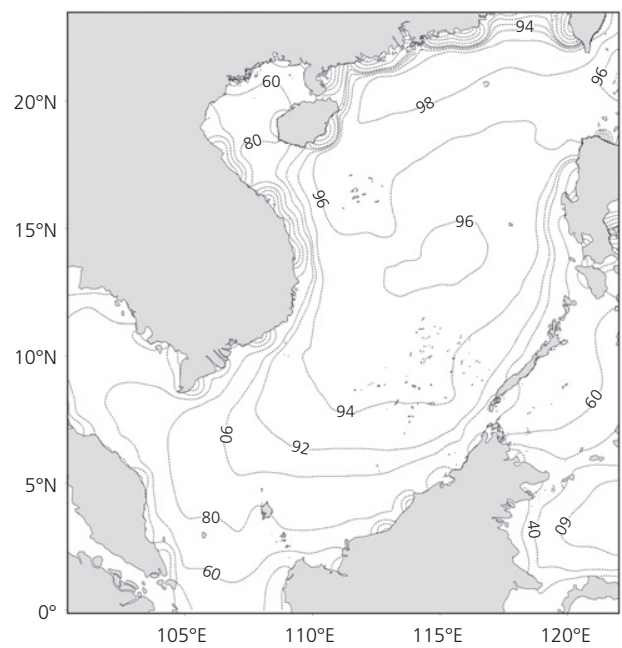

(e)

Figure 4. Annual and seasonal occurrences of the effective significant wave height over the past 37 years (unit: \%): (a) annual; (b) winter (DJF); (c) spring (MAM); (d) summer (JJA); (e) autumn (SON) 


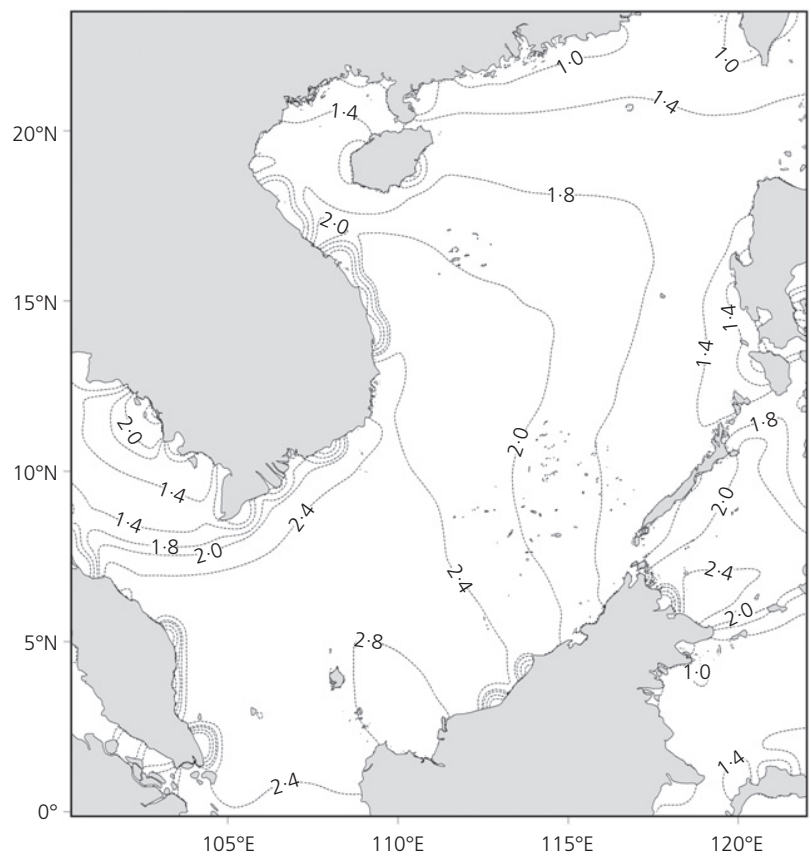

Figure 5. Distribution of MV index over the past 37 years

Table 3. Classification of MV index of wave energy flux (AQSIQ-SAC, 2017)

$\begin{array}{lc}\text { MV class } & \text { MV } \\ 1 & \leq 1 \\ 2 & 1-2 \\ 3 & 2-3 \\ 4 & >3\end{array}$

the HSSF is larger in winter and autumn than in spring and summer, which is consistent with the results presented in Section 3.1. Therefore, it is relatively difficult to use wave energy in areas where the energy is abundant due to the frequent occurrence of high sea states (Wan et al., 2015a). When choosing sites for wave energy farms, a balance must be achieved between the wave energy resource abundance and the HSSF.

\section{Conclusions}

In this study, based on the recent 37-year ERA-Interim reanalysis of wave field data, the wave energy resource of the South China Sea was assessed.

(a) The wave energy resource of the South China Sea was found to vary both seasonally and regionally. The wave energy resources in the South China Sea were highest in

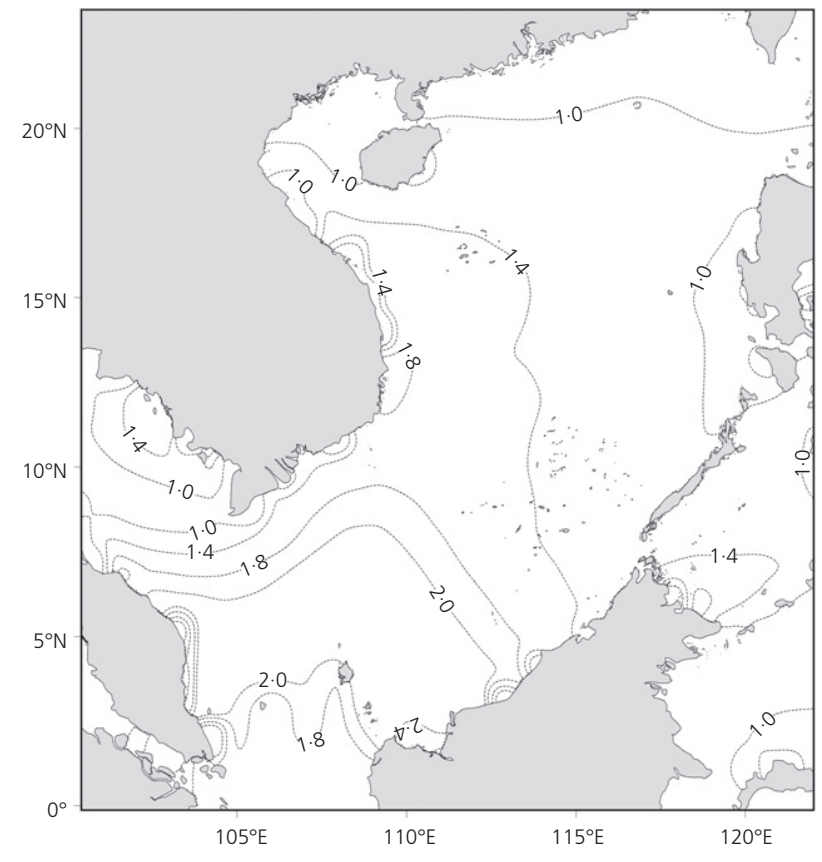

Figure 6. Distribution of SV index over the past 37 years

winter, when the wave energy flux was above $20 \mathrm{~kW} / \mathrm{m}$. The wave energy flux was largest in the area around the Dongsha Islands $(>8 \mathrm{~kW} / \mathrm{m})$ all year round.

(b) To ensure efficient use of energy, the effective significant wave height should be between 0.5 and $4 \mathrm{~m}$. The effective significant wave height in the South China Sea was generally high, and, with the exception of some areas near the equator and some coastal waters, was above $60 \%$ all year round. There is thus year-round potential for using the wave energy resource in the northern part of the South China Sea, while the resource in the southern part of the South China Sea could be exploited in winter.

(c) The wave energy flux was more stable in the northeast of the South China Sea than in the southwest. The wave energy was relatively stable in areas where the wave energy was abundant, which is beneficial for the development of wave energy. The distributions of the MV and SV indexes showed that areas south of the Indo-China Peninsula and northwest of Kalimantan Island were least stable.

(d) High sea states occurred more frequently in areas where there was abundant wave energy, meaning that it would be relatively difficult to use the wave energy. Therefore, when choosing sites for wave energy farms, there must be a balance between the level of wave energy resources and the frequency of high sea states. 


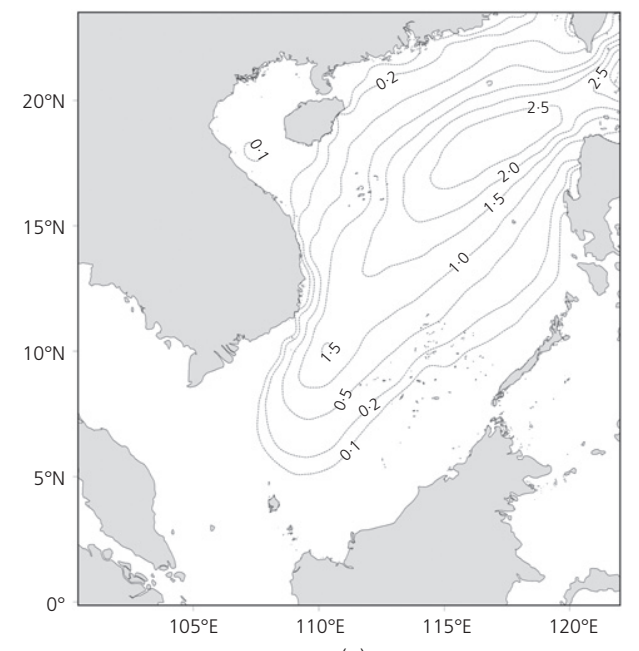

(a)

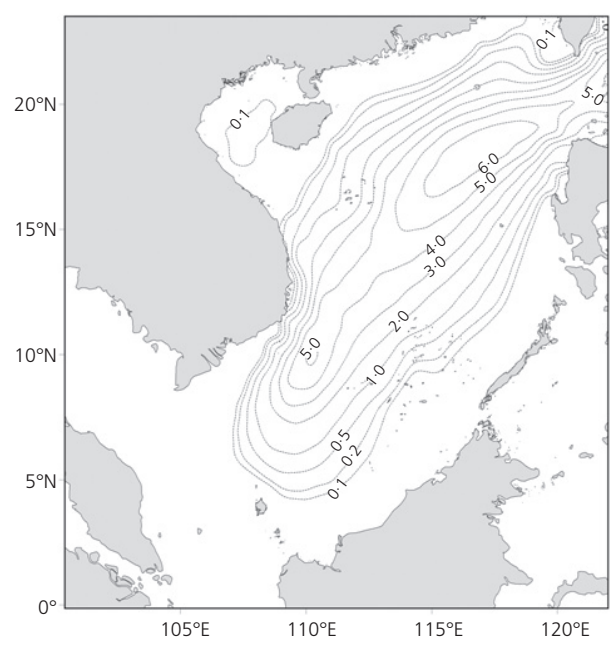

(b)

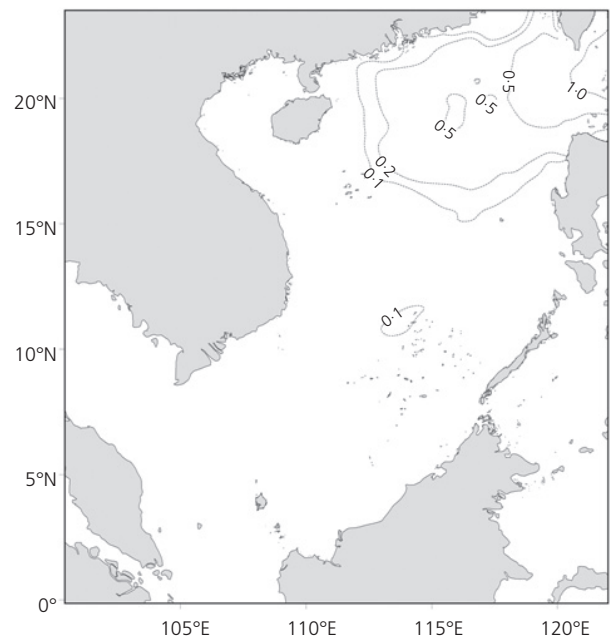

(d)

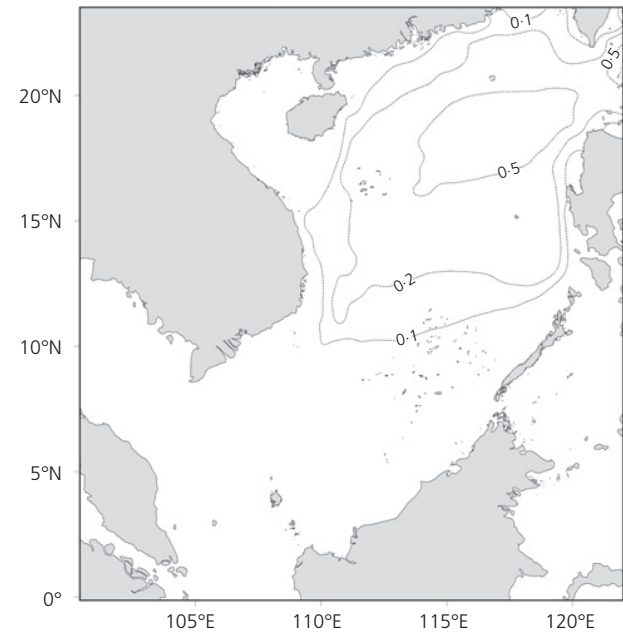

(c)

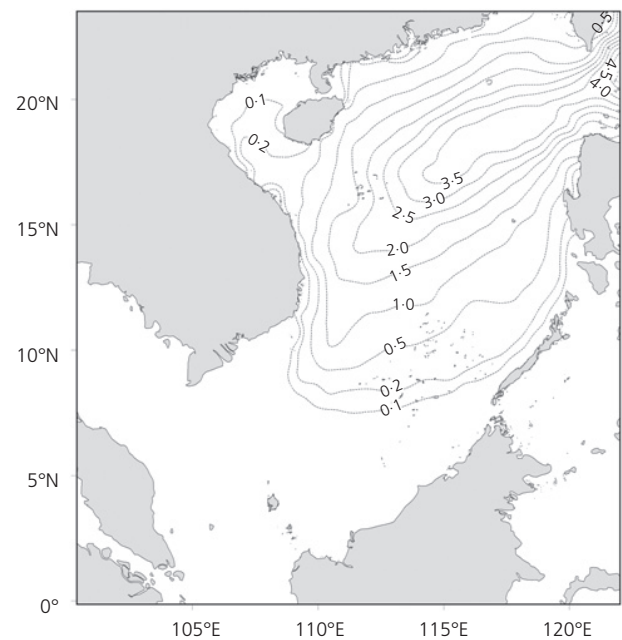

(e)

Figure 7. Distribution of the HSSF over the past 37 years (unit: \%): (a) annual; (b) winter (DJF); (c) spring (MAM); (d) summer (JJA); (e) autumn (SON) 


\section{Acknowledgements}

The authors acknowledge the ECMWF for providing the ERAInterim datasets. This study was supported by the National Natural Science Foundation of China (5171101175), Natural Science Foundation of Tianjin, China (16JCYBJC20600), National Marine Renewable Energy Programs of China (GHME2017ZC01, GHME2018ZC01). The authors also thank Liwen Bianji, Edanz Editing China (http://www.liwenbianji. $\mathrm{cn} / \mathrm{ac}$ ), for editing the English text of a draft of this paper.

\section{REFERENCES}

Andersson E (2013) User Guide to ECMWF Forecast Products. European Centre for Medium-Range Weather Forecasts, Reading, UK.

AQSIQ-SAC (Administration of Quality Supervision Inspection and Quarantine-Standardization Administration of the People's Republic of China) (2017) GB/T 34910.3: Guidelines for marine renewable energy resources survey and assessment. Part 3: wave energy. AQSIQ-SAC, Beijing, China.

Goncalves M, Martinho P and Soares CG (2014) Assessment of wave energy in the Canary Islands. Renewable Energy 68(C): 774-784.

Jiang B, Ding J, Wu H et al. (2017) Wave energy resources assessment along Bohai Sea, Yellow Sea and East China Sea. Acta Energiae Solaris Sinica 38(6): 1711-1716.

Liang BC, Fan F, Liu FS and Gao SH (2014) 22-year wave energy hindcast for the China East Adjacent Seas. Renewable Energy 71: 200-207.

Sheng SW, Wang KL, Lin HJ et al. (2017) Model research and open sea tests of $100 \mathrm{~kW}$ wave energy convertor Sharp Eagle Wanshan. Renewable Energy 113: 587-595.

Wan Y, Zhang J, Meng JM et al. (2014) Assessment of wave energy resources for the OE-W01 area based on ERA-Interim reanalysis data. Resources Science 36(6): 1278-1287.
Wan Y, Zhang J, Meng JM and Wang J (2015a) Exploitable wave energy assessment based on ERA-Interim reanalysis data - a case study in the East China Sea and the South China Sea. Acta Oceanologica Sinica 34(9): 143-155.

Wan Y, Zhang J, Meng JM and Wang J (2015b) Wave energy assessment in the East China Sea and South China Sea based on era-interim high resolution data. Acta Energiae Solaris Sinica 36(5): 1259-1267.

Wang CK (1984a) Primary analysis of the coastal wave energy source of China. Donghai Marine Science 2(2): 32-38.

Wang CK (1984b) Primary analysis of ocean energy source of China. Ocean Engineering 1984(2): 61-70.

Wang ZP, You YG, Sheng SW et al. (2017) Feasibility analysis of wave energy resource in South China Sea based on the open sea generation of Sharp Eagle wave energy convertor. Advances in New and Renewable Energy 5(2): 122-126.

Zhang S, Liu FY, Zhang B, Ma ZZ and Jiang B (2012) Investigation and assessment of wave energy in coastal area of China. Ocean Technology 31(3): 13-19.

Zheng CW and Pan J (2014) Assessment of the global ocean wind energy resource. Renewable and Sustainable Energy Reviews 33: $382-391$.

Zheng CW, Jia BK, Guo SP et al. (2013a) Wave energy resource storage assessment in global ocean. Resource Science 35(8): 1611-1616.

Zheng CW, Su Q and Liu TJ (2013b) Wave energy resources assessment and dominant area evaluation in the China sea from 1988 to 2010. Acta Oceanologica Sinica 35(3): 104-111 (in Chinese).

Zheng CW, Shao LT, Shi WL et al. (2014) An assessment of global ocean wave energy resource over the last 45 a. Acta Oceanologica Sinica 33(1): 92-101.

Zhou L, Zheng CW, Li J et al. (2011) Wave energy research in global oceans with ERA-40 wave data for recent 45 years. In Proceedings of the 2011 International Conference on Remote Sensing, Environment and Transportation Engineering (RSETE). Institute of Electrical and Electronics Engineers, , Piscataway, NJ, USA, pp. 3760-3763.

\section{How can you contribute?}

To discuss this paper, please email up to 500 words to the editor at journals@ice.org.uk. Your contribution will be forwarded to the author(s) for a reply and, if considered appropriate by the editorial board, it will be published as discussion in a future issue of the journal.

Proceedings journals rely entirely on contributions from the civil engineering profession (and allied disciplines).

Information about how to submit your paper online is available at www.icevirtuallibrary.com/page/authors, where you will also find detailed author guidelines. 